\title{
ENTREVISTA COM A GINECOLOGISTA E SEXÓLOGA TÂNIA DAS GRAÇAS MAUADIE SANTANA
}

\author{
por Ana Canosa
}

Tânia das Graças Mauadie Santana, é ginecologista, obstetra, especialista em terapia sexual e educação sexual pela Faculdade de Medicina do ABC e Sociedade Brasileira de Estudos em Sexualidade Humana (FMABC/SBRASH). Fundadora do Centro de Referência e Especialização em Sexologia (CRESEX), do Hospital Pérola Byington, que coordenou entre 1998 e 2014.

Como surgiu o interesse em implantar o atendimento a mulheres com queixas sexuais na rede pública de São Paulo?

Esse interesse surgiu da necessidade de atender a grande demanda de mulheres com queixas sexuais e observando a dificuldade e o despreparo dos profissionais para esse tipo de atendimento. Em 1984 fui convidada para trabalhar na Secretaria de Estado da Saúde de São Paulo para escrever as normas técnicas do Programa de Assistência Integral à Saúde da Mulher (PAISM) e implantar o Programa em todo o estado de São Paulo, junto com a equipe técnica da Coordenação Geral do PAISM. Concluída essa etapa, logo em seguida, fui designada para ser coordenadora do PAISM no ERSA I, região central da cidade de São Paulo, permanecendo nesse cargo até 1992, quando pedi para ser transferida para o Hospital Pérola Byington, que tinha sido revitalizado sob a direção do Prof. Dr. José Aristodemo Pinotti, para atender no Setor de Ginecologia Endócrina e Climatério. Por todas as minhas andanças pelo serviço público pude perceber a carência do atendimento específico na área da sexualidade. Sempre que chegava uma mulher com problema sexual nos diversos ambulatórios do Hospital, os colegas mandavam me chamar para atendê-la e o Dr. Pinotti me encaminhava as mulheres que pediam sua ajuda nas questões sexuais nos programas de rádio e televisão.

\section{Conte-nos como implantou o CRESEX no Hospital Pérola Bynghton - Centro de Referência de Saúde da Mulher em SP.}

Bem, o meu sonho era implantar o atendimento em sexualidade em todas as unidades da Rede Pública de São Paulo. No final do ano de 1997 eu estava terminando minha pós-graduação em Educação Sexual e Terapia Sexual na Sociedade Brasileira de Estudos em Sexualidade Humana (SBRASH) e fiz uma monografia para a conclusão do curso, que na verdade era o Projeto dos meus sonhos cujo título era Atendimento multiprofissional a mulheres com queixas sexuais no Hospital Pérola Byington. Eu estava com a monografia pronta para entregar na coordenação do curso da SBRASH quando cruzei com Dr. Pinotti esperando o elevador num dos andares do Hospital e ele me perguntou o que eu tinha nas mãos e eu mostrei o meu trabalho. Ele leu o título e nem pestanejou, apenas me disse: "Pode começar, jál" Na primeira semana de março de 1998 organizei e coordenei o $1^{\circ}$ Curso de Sensibilização em Sexualidade para equipe Multiprofissional e no dia 8 de março de 1998 foi inaugurado o Centro de Referência e Especialização em Sexologia (CRESEX), uma das primeiras experiências no Brasil no atendimento multiprofissional a mulheres com queixas sexuais, com a permissão e apoio do professor Pinotti que dirigia o Hospital na época. Além da atividade assistencial, o Serviço proporcionou treinamentos de equipes multiprofissionais, cursos de especialização e atualização em sexologia, jornadas, educação continuada e pesquisas científicas.

Sabemos que você valoriza o trabalho multiprofissional na área da sexologia. Foi desafiador elaborar o protocolo de atendimento do CRESEX nesse modelo?

Na época do Dr. Pinotti tudo funcionou bem e de acordo com a proposta inicial de trabalho, depois, com sua saída, o hospital passou por diversas diretorias que mudaram o seu perfil assistencial e acadêmico. Desde então, começou a haver muita resistência e dificuldade no trabalho de equipe por parte de algumas chefias dos diversos setores do Hospital. Por exemplo, quando eu menos esperava a chefe da enfermagem transferia a auxiliar de enfermagem treinada do nosso ambulatório para outro setor, assim como a própria diretoria pressionada por algumas chefias médicas transferiam nossos médicos, psicólogos e educadores para outros ambulatórios dizendo que eram "mais importantes". 
Enfim, eu comecei a ficar desanimada com o serviço público e a pensar em novos desafios.

Atualmente, o Hospital Pérola Bynghton mantém o serviço de sexualidade e forma profissionais com um curso de pós-graduação lato sensu em sexologia. Você ainda está envolvida nesses projetos?

Não, quando pedi demissão do Estado, em 20|4, já com 30 anos de serviço e 16 anos de trabalho no CRESEX, eu passei a coordenadoria para a equipe que restou pedindo que dessem continuidade àquele trabalho que foi uma das maiores razões da minha vida, mas, daquele momento em diante eu partiria para realizar novos sonhos.

Você fundou um núcleo de estudo da sexualidade no ambulatório de obstetrícia e antroposofia na Escola Paulista de Medicina. Essa foi mais uma das sementes que você plantou na Medicina?

Sim, além de implantar o ambulatório de sexualidade na Maternidade Leonor Mendes de Barros e de fornecer subsídios para a implantação de mais serviços na área da sexologia tanto em São Paulo como em outros estados do país, tive a honra de ser convidada para ajudar a fundar um núcleo de estudo em sexologia no Departamento de Obstetrícia da Escola Paulista de Medicina da Universidade Federal de São Paulo (UNIFESP/EPM). Este foi um dos trabalhos mais gratificantes da minha trajetória profissional, pois tive a oportunidade de conviver com pessoas especiais tanto pela qualidade humana como pela competência profissional. Elaborei conjuntamente com a equipe do CRESEX um programa de ensino abrangente da sexologia que foi realizado durante todo o ano 2007 e, a partir daí, têm sido apresentadas inúmeras teses de mestrado e de doutorado até os dias de hoje.

Após ter saído da rede pública você continua atuando na educação para a sexualidade no Projeto Arrastão (ONG), com adolescentes de 12 a 18 anos, voluntariamente. $O$ que te motiva a fazer esse trabalho?

Foi amor à primeira vista! Fui convidada para conhecer o Projeto Arrastão por uma amiga querida que estava iniciando seu trabalho como membro da diretoria e queria que eu the desse um apoio nesse seu novo desafio, daí nesse mesmo dia eu já fiquei envolvida e comecei a trabalhar como voluntária. A partir dos temas sobre sexualidade e saúde solicitados pelos adolescentes eu preparo um trabalho educativo. Faço reunióes frequentes com os monitores, professores e educadores e no final de cada semestre eu faço uma reunião com os pais. Durante um ano e meio de trabalho no Projeto pude constatar a necessidade de garantir, também, uma assistência médica para esses adolescentes que, em sua maioria, pertencem a um grupo de risco para gravidez precoce e DST. Por isso, eu pedi para montarem um consultório para eu mesma fazer o atendimento médico e solicitei uma retaguarda laboratorial para a realização dos exames complementares. $O$ que mais me motiva a fazer esse trabalho é contar com a colaboração, a boa vontade e o entusiasmo de todos, tanto da diretoria e dos funcionários como dos jovens que têm nos demonstrado um aproveitamento positivo com boa repercussão familiar. Acredito que realizando pequenos trabalhos como esse, podemos mudar o mundo para melhor!

Sei que você é baiana, mas viveu muitos anos em São Paulo. Agora se divide entre as duas cidades. São Paulo é um caso de amor?

Sim, vivo dividida em dois casos de amor: São Paulo e Salvador! Adoro Salvador, que é minha terra natal, onde curto muitos amigos e uma família enorme que eu amo. Além disso, tenho orgulho de ter estudado medicina na primeira faculdade do Brasil, fundada por D. João VI, onde meu pai também se formou e trago na lembrança a imagem de professores inesquecíveis. Além disso, a Bahia é mágica e abençoada pelos Orixás! Entretanto, eu amo também São Paulo, pois aqui eu tenho vivido feliz com minha família e com muitos amigos queridos há $4 \mathrm{I}$ anos. Há quatro anos eu inventei de abrir um consultório em Salvador para me sentir ainda mais útil nesta vida e sendo "obrigada" a ir mensalmente até lá para trabalhar, visitar amigos e parentes, aproveitando também pra ir à praia salgar o períneo, tomar água de coco e comer acarajé, que ninguém é de ferro!!!!

Ana Cristina Canosa Gonçalves Psicóloga e Especialista em Sexualidade Diretora de publicações da SBRASH - biênio $2018 / 19$ 